\title{
«LLORAR LOS OJOS Y CALLAR LOS LABIOS»: LA RETÓRICA DEL SILENCIO EN NO HAY COSA COMO CALLAR ${ }^{1}$
}

\author{
Carlos Mata Induráin \\ Departamento de Literatura Hispánica \\ Facultad de Filosofia y Letras \\ Edificio de Bibliotecas \\ GRISO-Universidad de Navarra \\ 31080 Pamplona. Navarra. España \\ cmatain@unav.es
}

[Anuario calderoniano (ISSN: 1888-8046), 3, 2010, pp. 259-274]

No hay cosa como callar, la comedia calderoniana en la que voy a centrar mi análisis, es sin duda una pieza interesante, pero que no cuenta hasta la fecha con una bibliografia demasiado nutrida. Un recuento (creo que bastante exhaustivo) de los trabajos dedicados específicamente a ella arroja el resultado de una veintena de entradas, a las que habría que sumar los estudios preliminares de las dos ediciones exentas modernas: la de Valbuena Briones en Clásicos Castellanos y la de Kathleen Costales como tesis doctoral de Vanderbilt University. No es ciertamente un registro escaso de trabajos críticos, pero tampoco cons-

${ }^{1}$ Este trabajo se integra en el Proyecto «Patrimonio teatral clásico español. Textos e instrumentos de investigación (TECE-TEI)", patrocinado por el Programa CONSOLIDER-INGENIO 2009, del Plan Nacional de I+D+I (código CSD2009-00033) del Ministerio de Ciencia e Innovación del Gobierno de España. 
tituye un volumen especialmente considerable ${ }^{2}$. Forma parte, pues, de ese corpus del "Otro Calderón", de esas obras suyas menos exploradas y que merecen, sin duda, una mayor atención por parte de los estudiosos.

\section{Cuestiones Preliminares: Del personaje donjuanesco al proble-} MA DE LA ADSCRIPCIÓN GENÉRICA

Comenzaré con un pequeño recordatorio del panorama textual de la comedia y de su datación. El texto se nos ha transmitido en ocho testimonios antiguos, tanto del siglo XVII como del XVIII, a saber: la edición princeps de Melchor Sánchez, en Parte diez y siete de comedias nuevas y escogidas de los mejores ingenios de Europa (1662); la edición de Vera Tassis, en la Séptima parte de comedias (1683); dos ediciones sueltas, sin datos de ciudad, editor ni año, formando parte de volúmenes pseudo-Vera Tassis; la reedición de Vera Tassis (1715); la edición de Apontes (1763) y las sueltas de Carlos Sapera (1766) y Francisco Suriá (s. a.). La obra contó con una refundición decimonónica debida a Bretón de los Herreros ${ }^{3}$.

Por lo que toca a la datación, la redacción de la comedia podríamos fijarla hacia el invierno de 1638-1639, como señala Hilborn y corrobora Valbuena Briones, poco después de los sucesos del sitio y defensa de Fuenterrabía, hecho histórico aludido en varios pasajes del texto $^{4}$. No he podido localizar datos de representaciones en el siglo XVII, pero sí se documentan varias en el XVIII, algunas de ellas con el título La banda y la venera 5 .

No hay cosa como callar, calificada de obra maestra por varios autores, ofrece muchos elementos de interés, comenzando por la consideración del personaje de don Juan de Mendoza y su relación con el origen del mito en El burlador de Sevilla. Tenemos aquí, en la come-

2 En la actualidad dirijo una tesis doctoral, la de Karine Delmondes, que tiene como objetivo el estudio y edición crítica de la pieza, dentro del proyecto global por parte de GRISO-Universidad de Navarra de edición crítica de las comedias calderonianas, bajo la dirección de Ignacio Arellano. Las citas del texto remiten a esta edición de Delmondes en preparación.

${ }^{3}$ Ver Cattaneo, 1993 y Vellón Lahoz, 1996.

${ }^{4}$ Ver Hilborn, 1938, pp. 35 y 41, y Valbuena Briones, 1954.

${ }^{5}$ Ver Coe, 1935. 
dia calderoniana, un burlador cínico, bellaco y locuaz, que constituye un eslabón bastante temprano en la larga cadena de recreaciones del personaje que se van a suceder a lo largo de los siglos. No voy a detenerme en esta cuestión ${ }^{6}$. Me bastará ahora con recordar la caracterización donjuanesca del personaje, que queda ya fijada en el diálogo inicial que mantiene con su criado Barzoque. Don Juan está melancólico porque cree que esta vez se ha enamorado de veras de cierta beldad que ha visto en la iglesia; pero Barzoque, que conoce bien el paño, se resiste a creer que pueda ser así:

BARZOQUe

¿Cómo? En siendo cara nueva, siempre es superior; que en ti la mejor es la postrera.

DON JuAn

Yo te confieso que he sido tan señor de mis potencias, de mi albedrío tan dueño, que no hay mujer que me deba cuidado de cuatro días; porque, burlándome dellas, la que a mí me dura más es la que menos me cuesta. (vv. 78-88)

Barzoque le pregunta qué pasa entonces con Marcela, la conquista anterior, y esta es la cínica respuesta de don Juan, que juega con la idea de una dama fija y otras errantes (a semejanza de las estrellas):

DON JUAN

Marcela

es dama de cada día:

ni entra, ni sale en la cuenta.

Todo ocioso cortesano

dice un adagio que tenga

una dama de respeto

que, sin estorbar, divierta,

y esta se llame la fija,

porque a todas horas sea

quien de las otras errantes

pague las impertinencias. (vv. 168b-178) 2009 .

${ }^{6}$ Algunos trabajos se han centrado en este aspecto, como el reciente de Costales, 
Otro asunto muy interesante es la complicada y discutida adscripción genérica de No hay cosa como callar: ¿comedia de capa y espada o drama serio?; y, muy en relación con lo anterior, la interpretación global del texto y de su desenlace: ¿final feliz, más o menos convencional, o no tan feliz, con un casamiento forzado y un desenlace que queda irresuelto ${ }^{7}$ y abre paso (en la línea de las ideas de Wilson y Wardropper) a una previsible tragedia futura? Creo que lo que ha suscitado las variadas interpretaciones y asimismo las distintas consideraciones genéricas de la pieza se deriva de la siguiente circunstancia: No hay cosa como callar es «externamente», esto es, en lo que se refiere a la ambientación (urbana, cercana al aquí y ahora del espectador del XVII), al enredo y a los elementos constructivos que maneja en el desarrollo de la acción, una comedia perfectamente asimilable al grupo de las de capa y espada. Tenemos una típica estructura pentagonal (dos damas y tres galanes), que dará lugar a sucesivos enredos de amores, celos y amistades traicionadas; tenemos también tres duelos en la calle (en el primero, don Juan ayuda a don Diego, que se veía acometido por tres contrarios, y esta detención le impide ir en seguimiento de la hermosa desconocida que acaba de ver en la iglesia; en el segundo, don Diego deja herido a un rival y debe refugiarse en casa de un embajador amigo, lo que propicia que su hermana Leonor quede sola en el domicilio familiar la noche del incendio; en el tercer duelo, a las puertas de la casa de Marcela, se enfrentan don Diego y don Juan y este se ve obligado a entrarse en casa de Leonor, circunstancia que propicia la reunión final de todos los personajes para el desenlace). Además, sucede el nocturno incendio de la casa de Leonor, que hace que deba salir medio desnuda y resguardarse en el domicilio de su vecino don Pedro; el vuelco del coche de Marcela, que será llevada a casa de don Diego para ser atendida, de resultas de lo cual el joven quedará enamorado de ella; hay ocultaciones de la personalidad de distintos personajes (don Juan relata a su compañero de armas don Luis la violación de una dama, circunstancia celebrada festivamente por este, ignorante de que se trata de su prometida...); tapadas (Marcela, celosa, sigue a don Juan al sospechar que una nueva pasión lo domina; Leonor acude tapada primero a ver a su hermano don Diego, y luego a casa de Marcela...); objetos de gran va-

${ }^{7}$ Ver Soufas, 1988.

Anuario calderoniano, 3, 2010, pp. 259-274. 
lor simbólico como la venera con un retrato femenino (la que Leonor consigue arrancar del cuello a su agresor la noche de la violación y que es su único testigo ${ }^{8}$, la única pista fiable que tiene para identificarlo, y que irá pasando de mano en mano), etc., etc.

Todos los mencionados son elementos, claramente, de comedia de enredo, a los que habría que sumar todavía diversas casualidades que se producen ${ }^{9}$ (así, el regreso de don Juan a su casa, de noche, para recuperar su hoja de servicios) y otros incidentes dramáticos que impulsan los diversos enredos de la acción, tan numerosos que hacen que en un determinado momento don Luis se pregunte: «¿Qué he de hacer en tan extraño / lance de amistad y celos, / de amor y honor?» (vv. 3287-3289a).

Sin embargo, todo ello se complica con la introducción de un elemento que viene a distorsionar esa estructura y a variar esa tonalidad de comedia de capa y espada. Me refiero, claro está, a la violación de Leonor por parte de don Juan (aunque ella no conocerá hasta bastante más adelante la identidad de su agresor), asalto brutal que ocurre al final del acto primero. Insisto: es esta combinación de ambiente, estructura y recursos de comedia de capa y espada con una tonalidad seria lo que ha desconcertado a parte de la crítica. Ciertamente, la acción de No hay cosa como callar no desemboca en tragedia (más allá de la enorme tragedia que supone la violación de la dama), ni hay propiamente una situación de riesgo trágico para los personajes; pero también es cierto que la acción se tiñe de una tonalidad seria inusual en las comedias de capa y espada.

Hay, por otra parte, un detalle importante en el tratamiento del tiempo. Entre el final del acto primero y el comienzo del segundo transcurren dos meses en los que Leonor se encastilla en el dolor y el silencio, sin posibilidad de hablar con nadie, salvo consigo misma cuando está a solas. Su pena, su dolor, su sufrimiento interior son enormes, y ese lapso de tiempo transcurrido (que rompe la concentración temporal propia de la comedia de capa y espada) es necesario aquí para la transformación psicológica del personaje, que tiene un antes y

${ }^{8}$ Ver Antonucci, 2003a, también para la relación con La dama duende. La crítica ha señalado ciertos puntos de contacto con la novela cervantina La fuerza de la sangre; ver, por ejemplo, Muir, 1985.

${ }^{9}$ Ver Hildner, 1993. 
un después del dramático suceso que ha sufrido. Ese tiempo elidido, $y$ toda la información que se nos ofrece acerca del proceso interior vivido por Leonor en su transcurso, son necesarios para redondear el carácter del personaje, que solo después de ese plazo pasará a tomar la iniciativa de procurar la identificación de su agresor, es decir, solo entonces tomará una actitud activa para recuperar su honor.

Al final, la acción no nos conduce al territorio de la tragedia (como sí lleva a la muerte trágica, por ejemplo, la misma circunstancia de una violación en El alcalde de Zalamea ${ }^{10}$ ); sin embargo, tampoco estamos ante una comedia en la que prevalezca la tonalidad cómica, que existe indudablemente, pero que no es continuada y no afecta a la mayoría de los personajes (no todos ellos son agentes cómicos). En el desenlace, cuando Leonor ya ha conseguido identificar a su violador y se encuentra en posición ventajosa para desenmascararlo, ella se decide a romper con su silencio:

LEONOR

Yo diré eso;

que aunque el silencio adoré, ya no es deidad el silencio, que hablar en tiempo es virtud, si es vicio el hablar sin tiempo (vv. 3372b-3376)

y se dispone entonces a contar en presencia de todos lo sucedido aquella trágica noche del incendio de su casa. Sin embargo, don Juan, al ver peligrar su consideración, le pide en un aparte que se calle y le ofrece el matrimonio. Todos los personajes implicados, enterados al menos de que hay algo raro atingente al honor, coinciden en señalar que, dadas las circunstancias, no hay cosa callar (es la formulación del título que irán repitiendo ahora todos a modo de estribillo o leit motiv). Don Juan, en esta ocasión, no da su mano a la justiciera estatua del Comendador, sino a la ultrajada víctima de su lujuria. Con este pacto de silencio entre don Juan y Leonor (y, por extensión, de todos los demás presentes) se salva el honor, queda restaurado ese valor que había sido transgredido, y se resuelve así el aspecto social del proble-

${ }^{10}$ Ver Casa, 1993, y también Mujica, 1979 y Costales, 2003. El hecho de que los personajes sean solteros es una circunstancia que facilita el final feliz propio de la comedia. 
$m a^{11}$, aunque sabemos que las dos personas que van a casarse no se aman. Es más, don Juan no ofrece su mano llevado de un arrepentimiento sincero, sino por miedo a que los demás conozcan su innoble proceder y su cobardía. Leonor, que estaba dispuesta a retirarse a la paz del claustro, acepta esa solución que le reintegra el honor, aunque su dignidad personal ha quedado bastante maltrecha en el camino. Como varios críticos han puesto de relieve, parece claro que en el desenlace de esta comedia triunfa el honor, mientras que el amor queda sacrificado en las aras del silencio, que vuelve a ser la deidad que lo preside todo.

Y existe todavía otro elemento disonante con respecto a las piezas usuales de capa y espada y sus convencionales finales felices: aquí el de don Juan y doña Leonor es el único matrimonio que se concierta, y no es que quede un galán suelto, sino que son tres los personajes que quedan desparejados; no hay, en efecto, otras bodas: don Luis, que amaba a Leonor, renuncia a ella para que pueda casarse con don Juan; Marcela quiere a don Juan, pero lo pierde también; don Diego, el hermano de Leonor, que está enamorado de Marcela, tampoco ve recompensado su esfuerzo amatorio.

En definitiva, podría decirse que No hay cosa como callar es una comedia bastante compleja, en el sentido de que bajo la apariencia o envoltura de una comedia de capa y espada se esconde un drama serio y, más aún, la impresión que deja en sus lectores (y en sus potenciales espectadores) es más bien la de una pieza de tonalidad intensamente dramática. Ni siquiera la acumulación de lances y peripecias (muy numerosos) provocados por sus múltiples enredos, ni tampoco los chistes del criado Barzoque (no demasiados, ciertamente) consiguen crear una atmósfera globalmente cómica. Lo reitero: la impresión predominante se acerca más al territorio de lo serio que al de lo cómico, y este aspecto de la tonalidad que capta el receptor (que empatiza con Leonor y siente rechazo por don Juan) me parece muy significativo: sin que se llegue a la tragedia, el regusto que nos deja la obra es agridulce.

11 La diferencia entre la afrenta personal y el agravio social en esta obra la comenta Casa, 1993, pp. 207-208. Para Neumeister (1982, p. 220), «El silencio sirve para apoyar el orden establecido". 
Espigaré a continuación varios juicios críticos a propósito de esta cuestión de la adscripción genérica. Escribe, por ejemplo, Dapaz Strout:

Pocos han sido los críticos que se han detenido en esta comedia, aunque todos ellos coincidan en considerarla una obra maestra a la par que se sienten incómodos, insatisfechos, por el casamiento «forzado» del final. La parquedad de los estudiosos del teatro de Calderón y lo problemático del desenlace concurren porque este drama gira alrededor de un tema perturbador, repelente y tabú: la violación ${ }^{12}$.

Por su parte, Rodríguez Cuadros habla de «la extraña comedia No hay cosa como callan, y aclara inmediatamente:

Uso el término extraña con toda la carga de prejuicios que arrancan de la perplejidad que produce una obra cuyo mapa estético de vocación trágica sólo se resuelve a última hora del lado restaurador y tópico de la comedia de capa y espada, y que culminan con la afirmación de los más lúcidos críticos del teatro de Calderón: la pieza es nemine discrepante la más seria e inclasificable de cuantas inscribiera en el género comediesco nuestro autor ${ }^{13}$.

\section{Por su parte, Valbuena Briones señalaba:}

Esta comedia es uno de los grandes aciertos de Calderón. La movilidad escénica, la perfecta estructuración, el interés de los episodios, la colocan, sin duda alguna, entre las primeras obras del dramaturgo. Comedia que, bordeando el drama, ágil de estilo, asombro de palabra, logro de caracteres, nos presenta el tipo de Don Juan como nuestro dramaturgo lo ve $\mathrm{e}^{14}$.

Déodat-Kessedjian, en su estudio de conjunto sobre El silencio en el teatro de Calderón de la Barca, escribe que No hay cosa es una obra

12 Dapaz Strout, 1981, p. 7.

13 Rodríguez Cuadros, 1988, p. 143. Y añade a continuación: «La incomodidad viene, probablemente, de la falta de nitidez de los componentes trágicos y cómicos de la pieza».

${ }^{14}$ Valbuena Briones, 1954, p. LXXXV (la cursiva es mía). Las opiniones de Valbuena Prat, en distintos trabajos, oscilan entre la consideración de la obra en las cercanías del drama o bien como comedia cómica (ver Valbuena Prat, 1941, pp. 164165; 1956, pp. 227-228; y 1969, p. 272). 
«totalmente atípica y difícil por lo tanto de clasificar»; de hecho, indica que le va a servir «de enlace entre el mundo de la tragedia y el mundo de la comedia» ${ }^{15}$.Y, efectivamente, le dedica un capítulo independiente titulado "Entre la tragedia y la comedia: No hay cosa como callar. Leonor: heroína del silencio».

Arellano ha señalado que no se trata de una comedia de capa y espada, sino de un drama serio:

En No hay cosa como callar, que a menudo se aduce como prueba de la seriedad de la comedia de capa y espada, la perspectiva global (no cómica), el nivel de implicaciones, la ausencia de risa y de personajes cómicos generalizados, el manejo del tiempo, la técnica de la premonición (característica de la tragedia calderoniana), la ausencia de enredo y los efectos que produce en el auditorio la frustración definitiva de la vida de Leonor, violada y casada contra su voluntad con el cínico Don Juan... llevan a una conclusión que me parece razonable: No hay cosa como callar no demuestra la tragicidad del género de capa y espada; simplemente no pertenece a él. Es un drama serio que Valbuena [Briones] debió haber editado en el tomo I de las Obras Completas que publicó en la editorial Aguilar ${ }^{16}$.

Pedraza, en cambio, defiende su pertenencia al terreno cómico, si bien destaca sus rasgos especiales al afirmar que No hay cosa como callar

es una extraña, turbadora comedia de capa y espada. Creo que, por única vez en el teatro de Calderón, los enredos y peripecias propios de las piezas ligeras se mezclan con un hecho grave y doloroso: la violación de doña Leonor por un galán desaprensivo y de vida disoluta ${ }^{17}$.

\section{Y añade después que}

conviene subrayar los originales perfiles de esta comedia, con sus ribetes trágicos y sus escabrosos episodios poco aptos para la risa. Se trata de una excepción, que confirma la regla, dentro del mundo de capa y espada. [...] comparte con la serie los usos onomásticos, el lugar y el tiempo, el

15 Déodat-Kessedjian, 1999, p. 244.

16 Arellano, 1988, p. 44.

17 Pedraza, 2000, pp. 228-229. 
ámbito de la acción y el final en boda. Excepcionalmente, el poeta ha dado un giro al tono de la comedia urbana y le ha conferido un sesgo trágico y sentimental ${ }^{18}$.

En fechas más recientes, Antonucci ha dedicado un par de trabajos a la comedia, uno de ellos centrado concretamente en este asunto de la adscripción genérica, y viene a concluir (parafraseo sus palabras traduciéndolas al español) que Leonor, no pudiendo conciliar amor y honor, se inclina por el honor; pero no por el hecho de que el honor prevalezca sobre el amor se puede negar a la pieza el estatus de comedia. Señala que se trata de un experimento teatral de Calderón, una suerte de exploración de los límites que permite la fórmula cómica, y destaca finalmente otro detalle que para ella permite adscribir No hay cosa al terreno de lo cómico: la victoria de Leonor sobre don Juan ${ }^{19}$.

Hay todavía otros puntos de interés en la pieza, que ahora me limito a señalar:

1) Todo lo relacionado con el hecho histórico que sirve de telón de fondo a la acción, que es la defensa de Fuenterrabía frente a los franceses; este hecho no está en primer plano de la comedia, pero el personaje de don Juan, soldado, parte para participar en esa jornada, y será precisamente la vuelta a casa para tomar los papeles de sus servicios militares, que se ha dejado olvidados, lo que propicie el encuentro nocturno con Leonor. Por supuesto, No hay cosa como callar no es un drama bélico de ambientación histórica, aunque sí se introduce un relato de la victoria española y una descripción de las celebraciones cortesanas ${ }^{20}$.

2) Otro aspecto interesante es la relación de un episodio de la comedia con otro mito, el de Fausto. Me refiero al momento en que don Juan dice que vendería su alma al diablo por encontrar de nuevo a la anónima beldad que ha visto en la iglesia e inmediatamente

18 Pedraza, 2000, pp. 230-231. Ver para más detalles Pedraza, 2005, pp. 466-467.

19 Antonucci, 2003b, p. 168. Costales, 2009, habla, por cierto, de un «don Juan domesticado".

${ }^{20}$ Sobre Calderón y Fuenterrabía, ver sobre todo Wilson, 1969. Valbuena Briones (1954, pp. LXVIII-LXXIX) relaciona este hecho histórico con la caracterización donjuanesca de don Juan de Mendoza. 
después, al abrir la puerta de su habitación, descubre dormida a Leonor, que es la hermosa desconocida ${ }^{21}$.

3) En fin, otros detalles dignos de comentario, en los que no puedo detenerme ahora, serían la consideración del gracioso Barzoque o la elaboración retórica de la obra.

\title{
2. LA RETÓRICA DEL SILENCIO
}

En No hay cosa como callar funciona toda una retórica del silen$\mathrm{cio}^{22}$, y no solo en su desenlace, sino desde el propio título ${ }^{23}$ y en buena parte de su desarrollo ${ }^{24}$, en el que vamos a encontrar claramente contrapuestos el silencio de Leonor y la locuacidad de don Juan: a diferencia del galán, que disfrutará relatando a don Luis las circunstancias de la violación, Leonor sufre y calla, y no puede contar a su hermano don Diego las razones de su profunda tristeza:

LEONOR

\author{
Si de causa naciera, \\ ¿a quién con más cariño la dijera? \\ Toda melancolía \\ nace sin ocasión, y así es la mía; \\ que aquesta distinción naturaleza \\ dio a la melancolía y la tristeza; \\ y para ella, los medios son más sabios \\ llorar los ojos y callar los labios. (vv. 1223-1230)
}

21 Este supuesto pacto diabólico ha sido interpretado como realmente existente por Wardropper, 1986 (y otros), pero no le veo al episodio una intencionalidad trágica; más bien al contrario, sirve para la caracterización cómica del gracioso, al poner de relieve su cobardía.

22 El tema del silencio en la literatura ha generado una bibliografia muy amplia; ver para el Siglo de Oro, entre otros muchos trabajos, Egido, 1986. Interesa recordar especialmente Béziat, 2004, para el teatro de Tirso y el ya citado de Déodat-Kessedjian, 1999, para el de Calderón. Con relación a No hay cosa, ver Soons, 1971; Dapaz Strout, 1981; Neumeister, 1982; Ter Horst, 1982; Iturralde, 1983; Sloane, 1984; Hesse, 1995; Déodat-Kessedjian, 1999, pp. 245-262; y Parker, 2000.

23 Título que, por cierto, responde a una formulación refranística, como en varias otras piezas calderonianas. Cabe recordar que el aprovechamiento en esta pieza de emblemas relacionados con el silencio ha sido estudiado por Soons, 1971.

24 También se pueden rastrear ejemplos a lo gracioso, como la caracterización de Juana como «criada / pitagórica, enseñada / solo a callar» (ver los vv. 2263-2273a). 
Este verso, que he elegido para el título de mi trabajo, resume a la perfección la situación anímica de Leonor, así como el escaso margen de acción que tiene. La joven únicamente puede expansionarse cuando se encuentra a solas, en soliloquios como este:

LEONOR ¡Oh, cuánto estimo verme desta suerte, pues pueden sin testigos mis enojos desahogarse! Hablad, labios; llorad, ojos. Solos estáis, decid vuestros agravios, quejaos al cielo, pues, ojos y labios, que aunque juré callar, siendo testigo el cielo, no es hablar hablar conmigo. (vv. 1274-1280)

Solo a solas pueden hablar sus labios, sin que por ello dejen de llorar sus ojos.Y en ese mismo soliloquio explicita las poderosas razones de su silencio (no puede contar nada, porque entonces su deshonor se publicaría y sería mayor):

LEONOR $\quad \ldots$ porque viendo al agresor

ya de mis ojos ausente, y que era entonces tan fácil no alcanzarle y conocerle, quise más callar, porque si yo una vez lo dijese y ninguna lo vengase, era afrentarme dos veces. (vv. 1335-1342)

En la incertidumbre de no conocer la identidad del «tirano» de su honor, sabe que su alma únicamente puede «padecer y callar» (v. 1529). $\mathrm{Y}$ en un monólogo posterior en el que apostrofa a su honor, le dice: «callemos, honor, tú y yo» (v. 2303), porque «en trances de honor, / "no hay cosa como callar"» (vv. 2309-2310).

Cuando en la escena final don Juan se refugia en la casa de su víctima, Leonor le muestra la venera que lo puede desenmascarar, pero prefiere no vengarse "porque a escándalo no pase / lo que hasta aquí fue silencio» (vv. 3219-3220); y añade:

LEONOR Yo soy mujer, finalmente, que moriré de un secreto 
por no vivir de una voz;

que, en fin, hablar no es remedio. (vv. 3225-3228)

Leonor pide a don Juan que calle él también pues está dispuesta a sepultarse viva en un convento; pero teme que, si la equívoca situación se prolonga y es descubierta a solas con un galán dentro de la casa, se vea en la necesidad de hablar:

LEONOR Con esto, idos; no mi hermano

vuelva, donde solo temo

un lance que a hablar me obligue,

siendo mi honor mi silencio. (vv. 3241-3244)

Esa circunstancia se produce finalmente: la llegada de don Diego, y de otros personajes, precipita el desenlace. Leonor se muestra decidida ahora a contar lo realmente sucedido aquella fatídica noche, pero don Juan la interrumpe, adopta el silencio como solución y resuelve el problema proponiéndole casamiento:

DON JUAN

... porque si en trances de honor

dice un discreto proverbio:

«no hay cosa como callar»,

de lo que hablé me arrepiento,

y no quiero saber más,

pues que no puedo hacer menos.

Esta es mi mano, Leonor. (vv. 3399-3405)

Vendrá después la retahíla de los demás personajes (don Luis, don Diego, don Pedro y Marcela) que irán repitiendo el mismo verso al final de sus respectivos parlamentos (ver los vv. 3406-3418). En fin, el gracioso Barzoque, en el ultílogo (vv. 3426-3430), remachará esa idea del silencio ocultador como solución final, esa retórica del silencio que impera sobre toda la acción de la comedia y los comportamientos de sus principales personajes ${ }^{25}$.

${ }^{25}$ Frutos Cortés (1949, p. 94) relaciona ese callar de los personajes al final de la obra con el silencio autobiográfico de Calderón. 


\section{Bibliografía}

Antonucci, F., «L'altra dama e il suo ritratto: somiglianze e differenze fra $\mathrm{La}$ dama duende e No hay cosa como callan, en Tra parola e immagine: effigi, busti, ritratti nelle forme letterarie, ed. L. Gentilli y P. Oppici, Pisa, Istituti Editoriali e Poligrafici Internazionali, 2003a, pp. 221-230.

- «Riflessioni su No hay cosa como callar e sulla sua appartenenza di genere», en Giornate Calderoniane Calderón 2000: atti del Convegno Internazionale, Palermo 14-17 Dicembre 2000, ed. E. Cancelliere, Palermo, Flaccovio Editore, 2003b, pp. 159-169.

Arellano, I., "Convenciones y rasgos genéricos en la comedia de capa y espada», Cuadernos de Teatro Clásico, 1, 1988, pp. 27-49.

BÉzIAT, F., El silencio en el teatro de Tirso de Molina, Pamplona / Madrid, Instituto de Estudios Tirsianos / Revista Estudios, 2004.

Calderón de la Barca, P., Comedias de capa y espada, II, «La dama duende» $y$ «No hay cosa como callar», ed. Á.Valbuena Briones, Madrid, Espasa Calpe, 1954.

- No hay cosa como callar, ed. K. Costales, Dissertation submitted to the Faculty of the Graduate School of Vanderbilt University, Nashiville, Tennessee, 2004.

- No hay cosa como callar, ed. K. Delmondes, Pamplona, Universidad de Navarra, tesis doctoral en curso.

CASA, F. P., «El tema de la violación sexual en la comedia», en El escritor y la escena. Actas del I Congreso de la Asociación Internacional de Teatro Español y Novohispano de los Siglos de Oro, ed. Y. Campbell, Ciudad Juárez, Universidad Autónoma de Ciudad Juárez, 1993, pp. 203-212.

Cattaneo, M., "Varianti del silenzio. No hay cosa como callar di Calderón e l'adattamento di Bretón de los Herreros», en De místicos y mágicos, clásicos y románticos, Messina, Armando Siciliano Editore, 1993, pp. 123-134.

Coe, M. A., Catálogo bibliográfico y crítico de las comedias anunciadas en los periódicos de Madrid desde 1661 hasta 1819, Baltimore, The Johns Hopkins University Press, 1935.

Costales, K., “"Honesta Venus” o “demonio vestido de mujer”: la percepción y el violador en No hay cosa como callan, Bulletin of the Comediantes, 55:1, 2003, pp. 129-153.

- «Don Juan domesticado o la desmitificación del tipo en No hay cosa como callar de Calderón», Bulletin of the Comediantes, 61, 1, 2009, pp. 109-128.

Dapaz Strout, L., «El casamiento "forzado" y el silencio ritual en No hay cosa como callan, Hispanic Journal, 3, 1, 1981, pp. 7-22.

Déodat-Kessedjian, M. F., El silencio en el teatro de Calderón de la Barca, Madrid / Frankfurt, Iberoamericana / Vervuert, 1999. 
EGIDO, A., "La poética del silencio en el Siglo de Oro: su pervivencia», Bulletin Hispanique, 88, 1986, pp. 93-120.

Frutos Cortés, E., Calderón de la Barca, Barcelona, Labor, 1949.

Hesse, E. W., «La subversión del acto de habla en No hay cosa como callar de Calderón», Boletín de la Biblioteca de Menéndez y Pelayo, 71, 1995, pp. 7585.

Hilborn, H. W., A Chronology of the Plays of D. Pedro Calderón de la Barca, Toronto, The University of Toronto Press, 1938.

Hildner, D. J., "Chronos y Kairos en el argumento calderoniano: el caso de No hay cosa como callan', en La Chispa '93 Selected Proceedings. The Fourteenth Louisiana Conf. on Hispanic Langs. E Lits., ed. G. Paolini, New Orleans, Tulane University Press, 1993, pp. 115-120.

ItUrRalde, J., «La mujer, el honor, el silencio en No hay cosa como callan,, Anuario de Letras Modernas (México), 1, 1983, pp. 35-42.

Muir, K., "Hardy, Middleton, Calderón, and Cervantes' La fuerza de la sangre», en Elizabethan and Modern Studies. Presented to Professor Willem Schrickx on the Occasion of His Retirement, ed. J. P. Vander Motten, Gent, Rijksuniversiteit Gent, 1985, pp. 181-189.

MujicA, B., "The Rapist and His Victim: Calderon's No hay cosa como callan, Hispania, 62, 1979, pp. 30-46.

Neumeister, S., «Saber y callar y otros ejemplos. Apuntes para una socio-patología del Siglo de Oro», en Actas del Coloquio hispano-alemán Ramón Menéndez Pidal, ed. W. Hempel y D. Briesemeister, Tübingen, Max Niemeyer Verlag, 1982, pp. 219-227.

PARker, A. A., "Sobre No hay cosa como callar y El médico de su honra», en Estudios sobre Calderón, ed. J. A. Maydeu, Madrid, Istmo, 2000, vol. 2, pp. 275-326.

Pedraza Jiménez, F. B., Calderón. Vida y teatro, Madrid, Alianza Editorial, 2000.

- «A vueltas con la taxonomía: La traición busca el castigo de Rojas Zorrilla», en Espacio, tiempo y género en la comedia española. Actas de las II Jornadas de Teatro Clásico de Toledo, Toledo, 14, 15 y 16 de noviembre de 2003, ed. F. B. Pedraza Jiménez, R. González Cañal y G. Gómez Rubio, Cuenca, Universidad de Castilla-La Mancha, 2005, pp. 453-483.

Rodríguez Cuadros, E., "Antes que todo es la acción: para una lectura de No hay cosa como callar de Calderón», Cuadernos de Teatro Clásico, 1, 1988, pp. 27-50.

SloAne, R., "Calderon's No hay cosa como callar: Character, Symbol, and Comedic Content», Modern Languages Notes, 99, 2, 1984, pp. 256-269. Soons, A., "Calderon Dramatizes an Emblem: No hay cosa como callan", Arcadia, 6, 1, 1971, pp. 72-74. 
SOUfas, T. S., "“Happy ending” as Irresolution in Calderon's No hay cosa como callan, Forum for Modern Languages Studies (Oxford), 29, 2, 1988, pp. 163174.

Ter Horst, R., «The Idioms of Silence. Cervantes, Honor, and No hay cosa como callan, en Calderon: The Secular Plays, Lexington, The University Press of Kentucky, 1982, pp. 69-170.

VAlbuena Briones, Á., «Don Juan, la ley burguesa y el cerco de Fuenterrabía. No hay cosa como callan, en el prólogo a su edición de P. Calderón de la Barca, Comedias de capa y espada, II, «La dama duende» $y$ "No hay cosa como callar», Madrid, Espasa Calpe, 1954, pp. LXXI-XCII.

Valbuena Prat, Á., Calderón. Su personalidad, su arte dramático, su estilo y sus obras, Barcelona, Juventud, 1941.

- Historia del teatro español, Barcelona, Noguer, 1956.

- El teatro español en su Siglo de Oro, Barcelona, Planeta, 1969.

Vellón LAhoz, J., "Moralidad y censura en las refundiciones del teatro barroco: No hay cosa como callar, de Bretón de los Herreros», Revista de Literatura, 115, 1996, pp. 159-168.

Wardropper, B. W., «El pacto diabólico callado en No hay cosa como callar, de Calderón", en Actas del VIII Congreso de la Asociación Internacional de Hispanistas: 22-27 agosto 1983, Brown University, Providence, Rhode Island, ed. A. David Kossoff, R. H. Kossoff, G. Ribbans y J. Amor y Vázquez, Madrid, Istmo, 1986, vol. 2, pp. 697-706.

Wilson, E. M., "Calderón y Fuenterrabía: el "Panegírico al Almirante de Castilla"”, Boletín de la Real Academia Española, 49, 1969, pp. 253-278. 